\title{
Computer studies of the operation of a Three-Phase Four Wire Shunt Active Power Filter applied to the Industry
}

\author{
Bruno Nova ${ }^{1, \#}$, Diogo Vaz ${ }^{1, \#}$, Paulo Passos ${ }^{1, \#}$, Nelson Andrade ${ }^{1, \#}$ \\ ${ }^{1}$ Centro ALGORITMI, University of Minho, Guimaraes, Portugal \\ \#bruno.nova@algoritmi.uminho.pt \\ \#diogo.vaz@algoritmi.uminho.pt \\ \#paulo.passos@algoritmi.uminho.pt \\ \#nelson.andrade@pt.bosch.com
}

\begin{abstract}
As the industry progresses, power quality problems become more and more relevant. The increase of non-linear loads in industries, leads to higher current harmonic distortion and low power factor. In order to mitigate these problems, this paper validates a shunt active power filter (SAPF). The adopted topology and its control algorithm are analyzed through computer simulations considering real industrial load models, which were elaborated from data collected in power quality analyzers that were connected to different points of an industry. The results achieved validate the correct operation of the applied SAPF, as well as it presents the improvements obtained of the total current distortion and neutral current.
\end{abstract}

Keywords: Industry 4.0, Power Electronics, Power Quality, Shunt Active Power Filter.

\section{Introduction}

The evolution of the industry and the consequent increase of non-linear loads on the factory facilities, increase the associated electrical power quality problems, namely harmonic distortion and low power factor [1]. These problems translate into unbalanced currents and excessive current in the neutral conductor, which can lead to overeating and deterioration of the installation. Furthermore, the harmonics and unbalances propagate to the voltages eventually causing the equipment malfunction [2].

With the arrival of industry 4.0, which aims to increasingly integrate sensors and smart meters designed to obtain large amounts of data from different variables of the facility, there is an opportunity to carry out more detailed analyses on the operation of installed equipment as well as the impact exerted under the quality of the electrical energy of the installation [3][4].

Traditionally, passive LC filters and capacitor banks are used to mitigate power quality problems. However, these solutions are usually not adaptable to dynamic loads and tend to be robust and expensive [5][6]. Given that, today's industry is designed not to consume reactive power, capacitor banks can present themselves as harmful solutions 
for the system, because they can contribute to increase the harmonic distortion of the system.

The shunt active power filters (SAPF) have been increasingly adopted due to their ability to perform real-time compensation. Depending on the control theory and hardware topology, it is possible to compensate in real time the harmonic currents, current unbalances as well as the low power factor [7]. The SAPF used in this study presents a three-phase four-wire power electronics converter. The Fryze-Buchholz-Depenbrock theory is used to calculate the reference currents to carry out the correct power management of the system [8]. In order to obtain results from real factory situations, the real loads of the factory, that is, production lines and electrical switchboards, were modeled in order to understand the effectiveness and benefits of the application of the SAPF. These loads are modeled in simulation using data collected by sensors employed at the factory.

Thus, this paper is divided into 6 sections. Section 1 presents the introduction to the paper as well as the topics approached. Section 2 presents the topology of the applied SAPF and its operation. Section 3 deals with the control algorithms used to control powers and currents. Section 4 refers to the reconstruction of the loads used, which is based on data provided by the factory sensors. Section 5 presents the simulation developed as well as the results obtained. Finally, section 6 presents the conclusions regarding the results obtained in simulation.

\section{Shunt Active Power Filter}

A shunt active power filter (SAPF) is an equipment connected in parallel to the electrical power grid functioning as a current source, used to compensate in real time, harmonics, current unbalances (in the case of three-phase installations) and power factor of an installation, through the production of reactive power and harmonic currents [9][10]. A SAPF can be single-phase or three-phase. The purpose of a SAPF is to make the currents in the electrical power grid sinusoidal and in phase with the power grid voltages, balance the current of the three phases which leading to a practically null neutral current [8][11]. The aim is to supply, from the electrical power grid to the loads, only the necessary active power. A SAPF allows a dynamic response, adjusting itself to the needs of the load and the conditions of the electrical power grid [12]. As a result of the operation of a SAPF, when compensating the current harmonics, it allows the decrease of the harmonic distortion of the grid voltage, as well as reducing the losses in the conductors. Since the RMS values of the currents are reduced, the losses in the conductors are also decreased.

There are several hardware topologies for the SAPF such as a three-wire converter with one dc-link, a three-wire converter with two dc-links, where the neutral is connected to the midpoint of the two dc-links, and the four-wire converter topology here the neutral conductor connects to the fourth leg [13].

The chosen SAPF topology for this study consists of a two-level four-wire voltage source inverter (VSI), which uses 08 IGBTs and a capacitor in the dc-link. The use of a four-wire topology allows to compensate for the neutral current. Fig. 1 shows the 
block diagram of the three-phase four-wire SAPF. The inductance (L) is used to connect the inverter to the power grid.

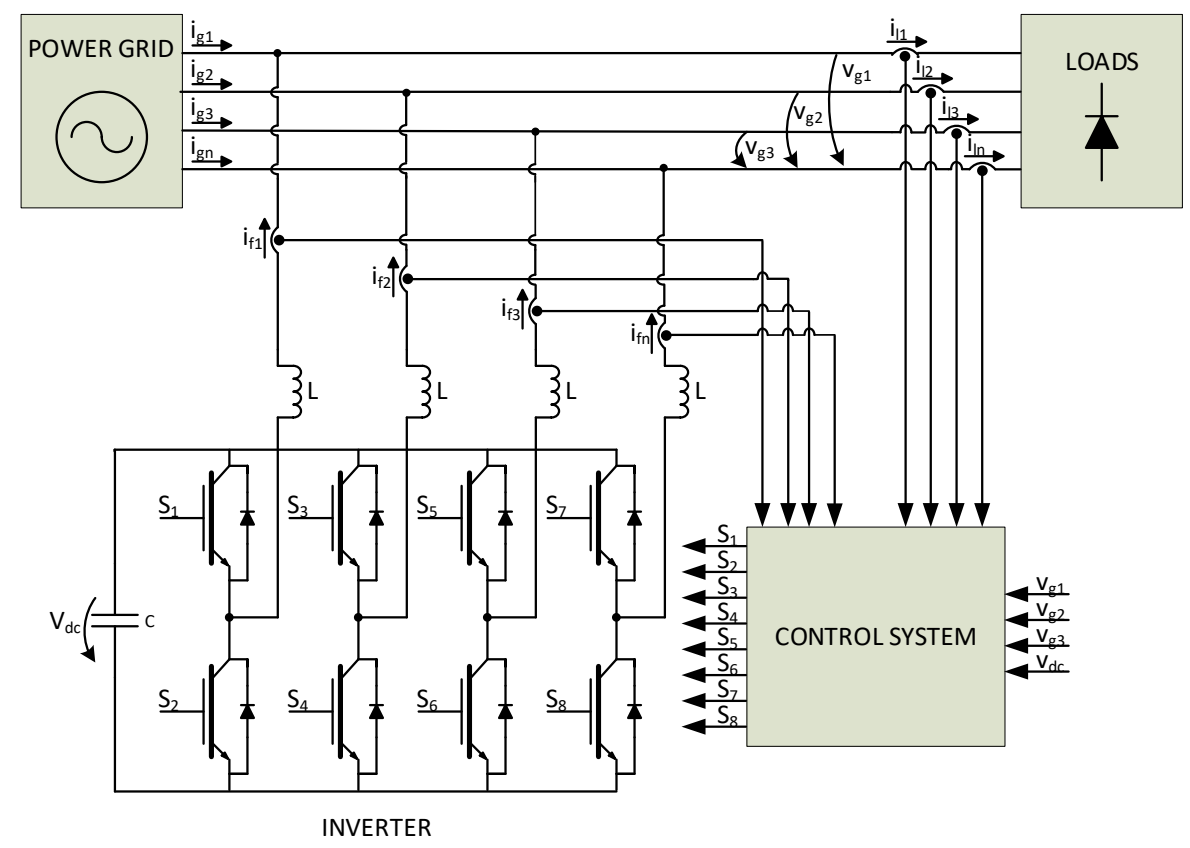

Fig. 1. Schematic of the SAPF simulation model.

By using sensors to measure the loads currents, the currents in the SAPF and the power grid voltages, the control system generates the gate signals to the switching devices, so that the currents in the grid $\left(i_{g 1}, i_{g 2}, i_{g 3}\right)$ are balanced and in phase with the voltages $\left(v_{g l}, v_{g 2}, v_{g 3}\right)$ and the current in the neutral $\left(i_{g n}\right)$ is practically zero.

\section{Control Algorithm}

The purpose of the SAPF is to compensate harmonic currents present in the load side. To calculate the compensation reference currents, the Fryze-Buchholz-Depenbrock (FBD) power theory is used. This power theory is implemented in the time domain and is based on the idea of representing a load by its conductance in parallel with a harmonic current source and a reactive element [14]. The conductance corresponds to the power component of the load that the grid must supply, i.e., the active power. To applicate this theory, it is calculated the average value of the total instantaneous power consumed by the loads, which correspond to the active power. The active power is divided by three, to be equally divided by the three phases. The explanation of the next steps of the FBD theory, will be done for one phase and for the other two phases the procedure is the same, being only replicated [15]. 
Knowing that the conductance is the inverse of the resistance and knowing the active power value for each phase $\left(P_{l}\right)$ and the power grid RMS voltage $\left(V_{G l}\right)$, the conductance is defined by equation ( 1$)$. To calculate the value of the reference current $\left(i_{\text {glref }}\right)$ equation (2) is applied, where $v_{g}$ is the instantaneous value of the voltage. Since the grid voltage may be distorted, a phase locked-loop (PLL) algorithm is applied in order to perform synchronization with the grid voltage.

The PLL algorithm produces a sinusoidal signal in phase with the fundamental component of the grid voltage [16]. The produced signal is used for the calculation of the reference current, allowing the reference current to be sinusoidal even for a distorted voltage. Replacing in equation (2) the grid voltage by the PLL $\left(v_{p l l 1}\right)$ gives equation (3). Knowing the reference current for the grid and the current at the loads $\left(i_{l 1}\right)$, apply equation (4) to calculate the reference current for the SAPF $\left(i_{\text {flref }}\right)$, and this reference current is then applied on the current control.

$$
\begin{gathered}
G_{1}=\frac{P_{1}}{V_{G 1}^{2}} \\
i_{g 1 r e f}=G_{1} v_{g 1} \\
i_{g 1 r e f}=G_{1} v_{p l l 1} \\
i_{f 1 r e f}=i_{l 1}-i_{g 1 r e f}
\end{gathered}
$$

For the semiconductor switching, the periodic sampling technique is applied. This technique is widely used and it is simple to implement. Fig. 2 shows the block diagram. This technique defines a maximum value for switching frequency, not having a fixed switching frequency [17].

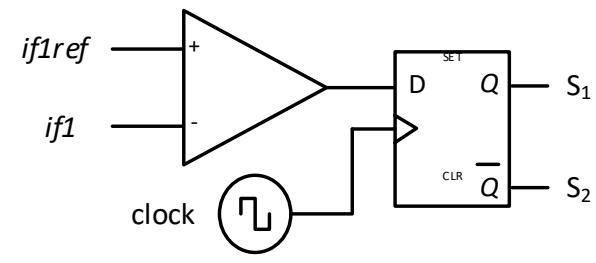

Fig. 2. Schematic of the periodic sampling switching technique.

The periodic sampling technique works as follows, when the reference current $\left(i_{\text {flref }}\right)$ is higher than the SAPF current $\left(i_{f l}\right)$, the $S_{1}$ semiconductor is switched ON and the $S_{2}$ semiconductor is switched OFF. If the reference current is lower than the current in the filter the bottom semiconductor is switched ON. The clock frequency has been set to $100 \mathrm{kHz}$, meaning that the maximum switching frequency is $50 \mathrm{kHz}$. 


\section{$4 \quad$ Industrial Loads}

As the factory under analysis has taken a step forward into the industry 4.0, it has employed different power quality analyzers throughout its system. These analyzers (sensors), allow a more precise analysis of the installed electrical system. As such, data of the RMS values of the voltage, current and their waveforms, harmonic distortion, power factor, among others, are taken.

With this data it is possible to define the different loads both theoretically, resorting to the manufacturer's datasheets, and practically through the data recorded at regular intervals (programmed by the user). It is also possible to check the data and waveforms in real time. Thus, in the case study used for this situation, there are very different loads, but these will be divided into two groups, air conditioning system (HVAC) and line productions switchboards (electrical switchboards). Note that only these main loads are considered, as they are the ones with the highest power consumption and make the study more generic.

\subsection{HVAC System}

The air conditioning system consists of two switchboards where four air treatment units (ATUs) are connected in each, and five equal independent chillers. The ATUs are divided into two switchboards due to belonging to different areas of the industrial complex and the five chillers are distributed throughout the industrial complex.

Regarding the ATUs there are two types, which are presented in Table 1. The data presented are taken from the builder's plates. In one of the tables there are four type 1 ATUs and in the other table there are four type 2 ATUs. In Table 1, it is also presented the type of chiller applied as well as its characteristics

Table 1. Characteristics of ATU of type 1, type 2 and chillers.

\begin{tabular}{|c|c|c|c|c|c|}
\hline & Voltage $(\mathrm{V})$ & Frequency $(\mathrm{Hz})$ & Power $(\mathrm{kW})$ & Current $(\mathrm{A})$ & Power Factor \\
\hline Type 1 & 400 & 50 & 23 & 33.53 & 0.99 \\
\hline Type 2 & 400 & 50 & 24.6 & --- & --- \\
\hline Chiller & 400 & 50 & 326.8 & 497 & 0.95 \\
\hline
\end{tabular}

Through the analyzers, it was possible to extract other data about these two switchboards of the HVAC system. A complete month of the year 2021 was analyzed and the monthly average value was taken for the current consumed, apparent power, harmonic distortion of the current (THD\%I) and power factor. In the case of the switchboard of ATU type 1. The Table 2 presents the summarized data for selected month. Note that in this month this switchboard presents a current unbalance between the three phases of $2.11 \%$ and that the variable L1, L2, L3 refers to the three phases of the system 
Table 2. Monthly average value of current, apparent power, THD\%I and power factor of the ATU type 1.

\begin{tabular}{cccc}
\hline Month Average & L1 & L2 & L3 \\
\hline Irms (A) & 187.92 & 193.65 & 194.84 \\
\hline Power (kVA) & 39.6 & 40.93 & 41.61 \\
\hline THD\%I (\%) & 43.51 & 41.68 & 39.17 \\
\hline Power Factor & 0.90 & 0.91 & 0.91 \\
\hline
\end{tabular}

In Table 3, it is presented the same data that was shown for the Type 2 switchboard. In this type 2 switchboard an average monthly current unbalance of $1.43 \%$ was calculated.

Table 3. Monthly average value of current, apparent power, THD\% I and power factor of the ATU type 2.

\begin{tabular}{cccc}
\hline Month Average & L1 & L2 & L3 \\
\hline Irms (A) & 145.47 & 146.77 & 147.29 \\
\hline Power (kVA) & 30.6 & 30.85 & 30.85 \\
\hline THD\%I (\%) & 42.33 & 42.57 & 41.51 \\
\hline Power Factor & 0.90 & 0.91 & 0.90 \\
\hline
\end{tabular}

In addition to these calculated data, it was possible to obtain the waveform of these two at specific frames, through an Excel file generated by the analyzers with several points of the current waveform. In Fig. 3 and Fig. 4, the current in the Type 1 and Type 2 switchboard is presented, where the currents of phases L1, L2 L3 and neutral (N) are shown.

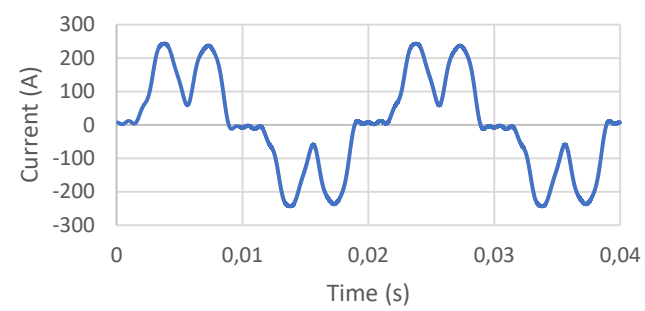

(a)

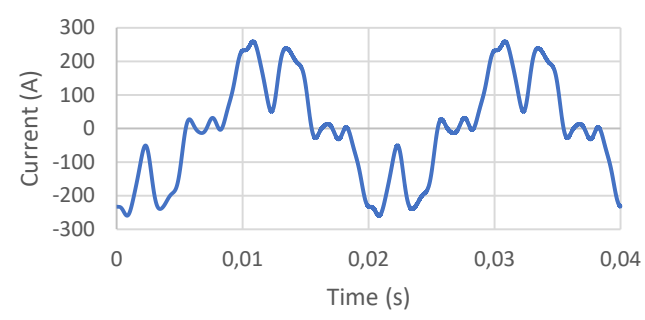

(b) 


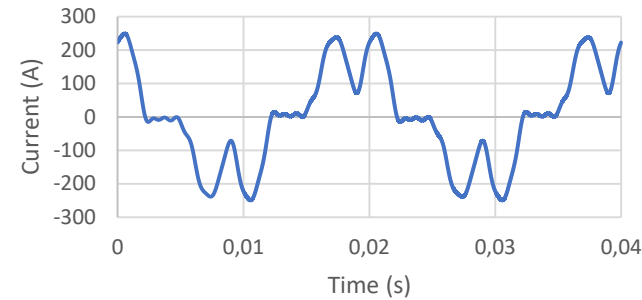

(c)

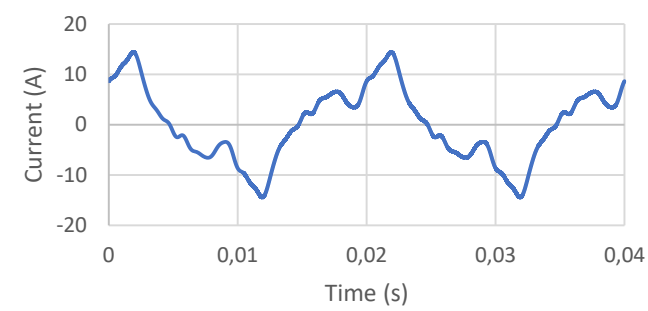

(d)

Fig. 3. Current waveform of the ATU of type 1: (a) L1 (b) L2 (c) L3 (d) neutral.

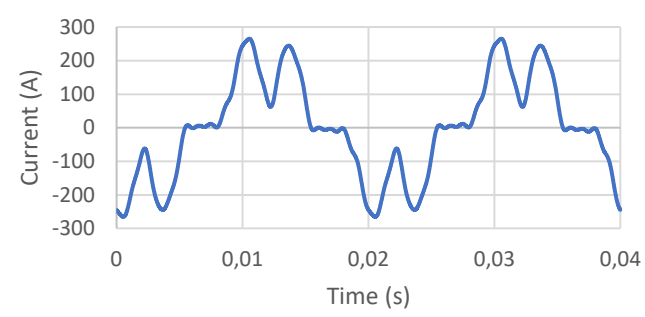

(a)

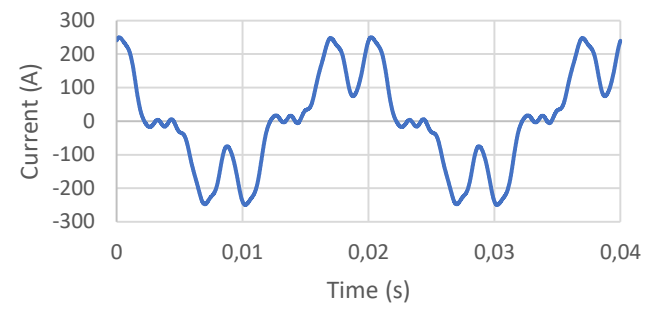

(b) 


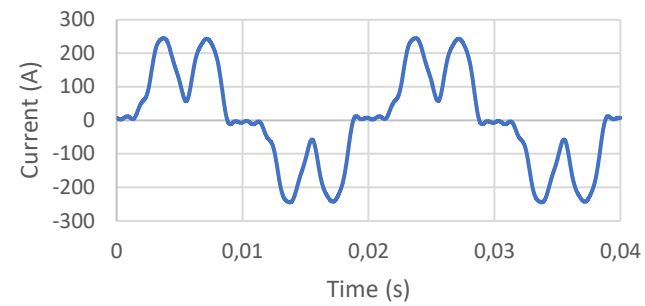

(c)

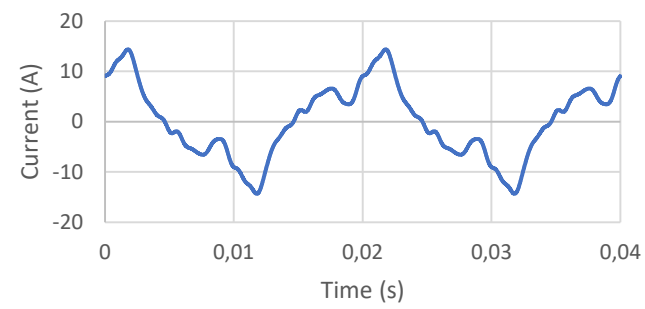

(d)

Fig. 4. Current waveform of the ATU of type 2: (a) L1 (b) L2 (c) L3 (d) neutral.

For the five chillers, only one was analyzed due to the fact that they are all equal. The same happens to the two HVAC switchboards. So, through the data recorded by the analyzers, over the same month, and applying a monthly average, Table 4 is obtained. In addition to this data, the current unbalance calculated through the monthly data of the currents of the three phases resulted in $4.44 \%$ unbalance between the three phases, although the monthly average value of the current does not show this unbalance. The waveform of this chiller, in operation, can be seen in Fig. 5.

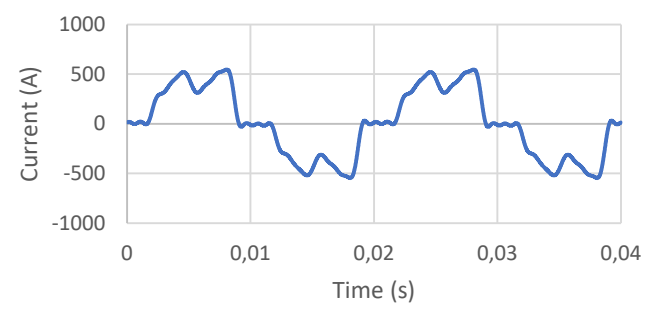

(a)

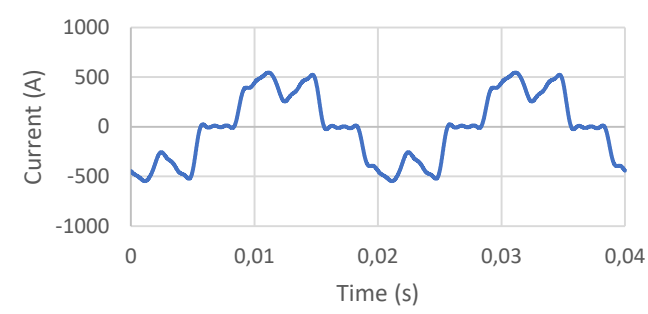


(b)

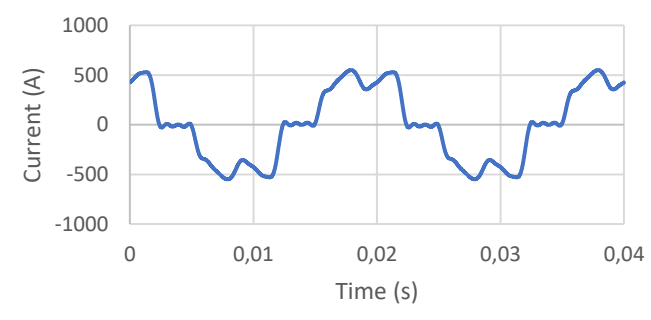

(c)

Fig. 5. Current waveform of the chiller: (a) L1 (b) L2 (c) L3.

Table 4. Monthly average value of current, apparent power, THD\% I and power factor of the Chiller.

\begin{tabular}{cccc}
\hline Month Average & L1 & L2 & L3 \\
\hline IRMs (A) & 41.94 & 42.52 & 43.57 \\
\hline Power (kW) & 8.6 & 8.72 & 8.87 \\
\hline THD\%I (\%) & 30.8 & 56.17 & 53.71 \\
\hline Power Factor & 0.71 & 0.75 & 0.43 \\
\hline
\end{tabular}

\subsection{Electrical Switchboard}

The electrical switchboards are used to ensure a better management and protection of the production lines throughout the case study analyzed. In general, in each switchboard it is possible to connect about four production lines, thus allowing a better protection of each line (because it can be made individual protection of machines and the application of smaller protections) and facilitating the management of them each time it is necessary to make adjustments. For this case study, an electrical switchboard is considered, which is normally the set of four production lines. For a brief contextualization, one of the production lines analyzed contains three-phase and single-phase machines. In the set of three-phase machines there is a combination of maximum theoretical power of $98.2 \mathrm{kVA}$, in the set of single-phase machines of $6.7 \mathrm{kVA}$ and a THD\%I between $5.5 \%$ and $6.5 \%$.

That said, and as presented in the previous section, the monthly average value of the consumed current, apparent power, harmonic distortion of the current and power factor was done through the power quality analyzers. Table $\mathbf{5}$ presents the monthly average values. It was possible to calculate the unbalance between the phases of the electric board, which resulted in an unbalance of about $7.17 \%$. 
Table 5. Monthly average value of current, apparent power, THD\% I and power factor of the Electrical Switchboard.

\begin{tabular}{cccc}
\hline Month Average & L1 & L2 & L3 \\
\hline IRMS (A) & 157.6 & 139.98 & 161.51 \\
\hline Power (kVA) & 36.89 & 32.08 & 37.39 \\
\hline THD\%I (\%) & 11.63 & 13.12 & 13.62 \\
\hline Power Factor & 0.98 & 0.98 & 0.98
\end{tabular}

In addition to these values calculated using the data recorded by the analyzers, the waveform of the current for an instant, from the analyzed switchboard, was also taken. This waveform is shown in Fig. 6.

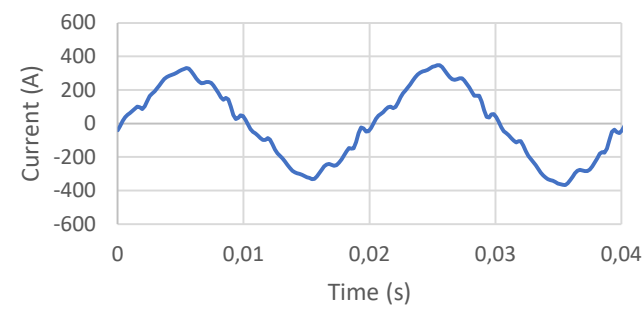

(a)

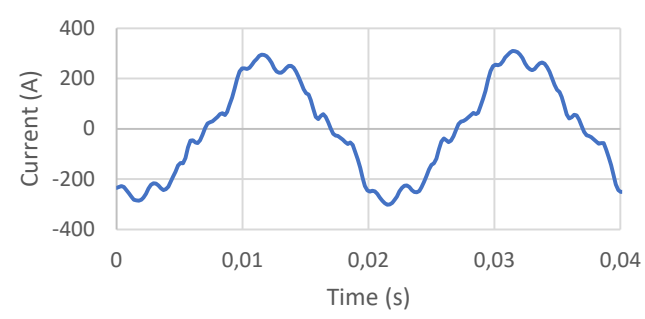

(b)

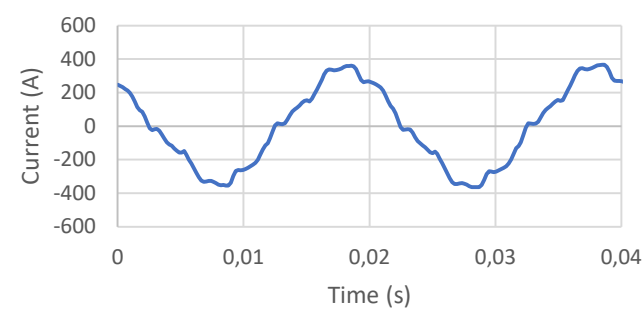

(c) 


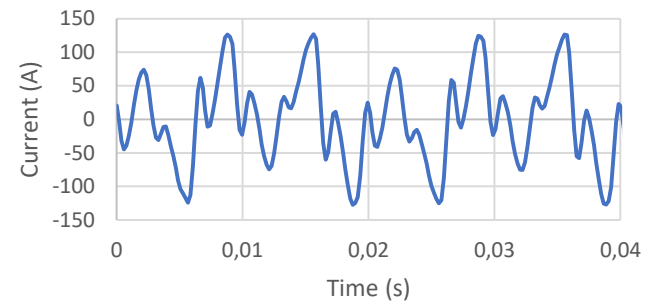

(d)

Fig. 6. Current waveform of the electrical switchboard: (a) L1 (b) L2 (c) L3 (d) neutral.

\section{$5 \quad$ Simulation and Results}

In section 2 was presented the electrical scheme of the SAPF used in this study. In order to validate its correct functioning with the factory loads, two different situations were designed. For both situations the SAPF only starts its operation after the instant of $0.2 \mathrm{~s}$ and the considered loads are: 5 chiller equipment, $2 \mathrm{HVAC}$ electrical switchboards and 10 electrical switchboard that provide power to the production lines.

-Scenario 1: In the first approach, it was considered that there are 5 chillers and 12 electrical switchboards in operation, however, it is considered that the 5 chillers and 2 HVAC electrical switchboards are on the load side and the remaining 10 electrical switchboards are on the grid side. This means that the 5 chillers and the 2 HVAC electrical switchboards are being compensated by the SAPF and that the remaining 10 electrical switchboards are not compensated.

-Scenario 2: In a second approach the inverse is done, that is, the 5 chillers and the 2 HVAC electrical switchboards are now on the grid side and the remaining 10 electrical switchboards are on the load side. Thus, the 10 switchboards are being compensated by the developed SAPF while the 5 chillers and HVAC switchboards are not compensated.

In order to simulate these two scenarios, it was necessary to create models of the factory loads. To do this, the data provided by the installed sensors was collected, where the Fast Fourier Transform (FFT) was applied, in order to obtain the values of magnitude and phase for each harmonic component associated to currents in the production lines, electrical switchboards and HVAC equipment and also the voltages of the transformers in parallel. The Fig. 7 presents the voltage values of transformer 1 and transformer 3 when both are operating in parallel. 


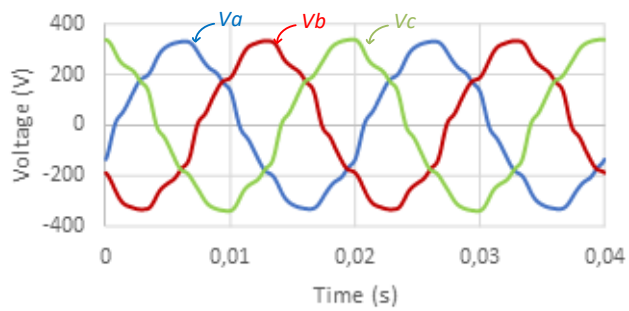

Fig. 7. Voltage waveform of the coupling point of transformer 1 and 3.

In this situation the voltage values for L1 are $231.1 \mathrm{~V}, \mathrm{~L} 2$ is $229.8 \mathrm{~V}$ and L3 is 232.7 V. It is also noted that the THD values recorded are $5.7 \%$ for $\mathrm{L} 1,6.34 \%$ for $\mathrm{L} 2$ and $6.35 \%$ for L3.

In section 5.1 and section 5.2 it is presented the results obtained for both Scenario 1 and Scenario 2 respectively.

\subsection{Scenario 1}

In this scenario, all the proposed loads are connected to the system, but only the 5 chillers and the 2 HVAC switchboards are being compensated. The results presented in Fig. $\mathbf{8}$ are the grid currents, when considering all the connected loads.

The Fig. 8 shows the grid currents waveforms for before and after the SAPF operation.

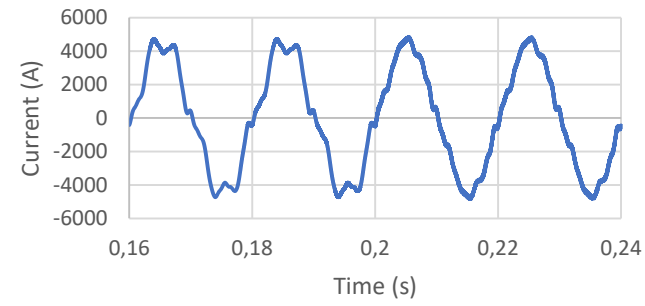

(a)

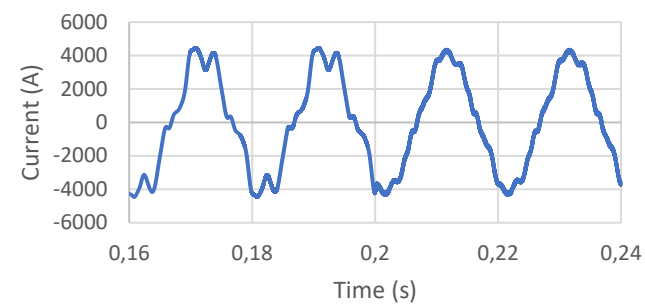

(b) 


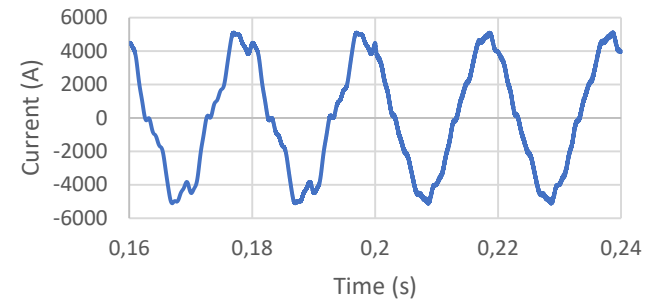

(c)

Fig. 8. Current waveform of the power grid, before and after the SAPF is turn-on in instant $0.2 \mathrm{~s}$ : (a) L1 (b) L2 (c) L3.

Before the SAPF operation, the grid currents present values of 3168 A at L1, 2933 $\mathrm{A}$ at $\mathrm{L} 2$ and $3370 \mathrm{~A}$ at L3. With regard to THD\%I, it should be noted that this presents a value of $16.38 \%$ at L1, $20.59 \%$ at L2 and $16.70 \%$ at L3. Subsequently, it is possible to observe the compensation of the currents carried out by the SAPF, where a grid-side current of $3132 \mathrm{~A}$ at L1, $2851 \mathrm{~A}$ at L2 and $3328 \mathrm{~A}$ are recorded. The THD\%I is significantly reduced to $7.8 \%$ at L1, $8.94 \%$ at L2 and $7.35 \%$ at L3. Table 6 presents these results.

Table 6. THD\% I and grid current values before and after the parcial compensation of the loads.

\begin{tabular}{|l|c|c|c|c|}
\hline & \multicolumn{2}{|c|}{ Before Compensation } & \multicolumn{2}{c|}{ After Compensation } \\
\hline & THD\%I & Current Values (A) & THD\%I & Current Values (A) \\
\hline L1 & 16.38 & 3168 & 7.8 & 3132 \\
\hline L2 & 20.59 & 2933 & 8.94 & 2851 \\
\hline L3 & 16.70 & 3370 & 7.35 & 3328 \\
\hline
\end{tabular}

Fig. 9 presents the grid reference currents that are calculated by the implemented control algorithm.

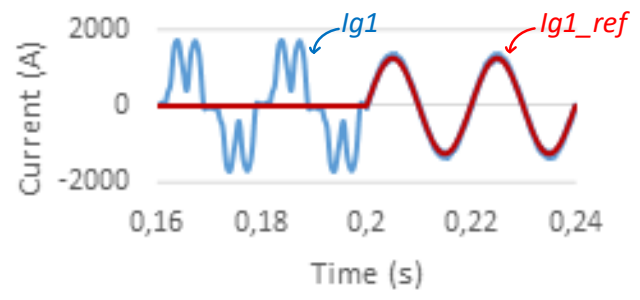

Fig. 9. Current waveform of the power grid $I g I$ and the reference $I g 1 \_r e f$ generated by the control system.

Fig. 10 shows the current waveforms of the loads that will be compensated. These loads are the chiller and the 2 HVAC electrical switchboards. It can be observed that at 
this point the current values are $1011 \mathrm{~A}$ at L1, $1042 \mathrm{~A}$ at L2 and $1015 \mathrm{~A}$ at L3. Regarding the THD\%I values, $46.89 \%$ is observed for $\mathrm{L} 1,45.06 \%$ for $\mathrm{L} 2$, and $44.68 \%$ for L3. After $0.2 \mathrm{~s}$ the moment when the SAPF begins to act, it can be seen that the current and THD\% I values are reduced. There is a current value of $915 \mathrm{~A}$ at L1, $918 \mathrm{~A}$ at L2 and $918 \mathrm{~A}$ at L3. THD\% I has been reduced to $3.98 \%$ for $\mathrm{L} 1,4.06 \%$ for $\mathrm{L} 2$ and $3.96 \%$ for L3. Such results are highlighted in Table 7.

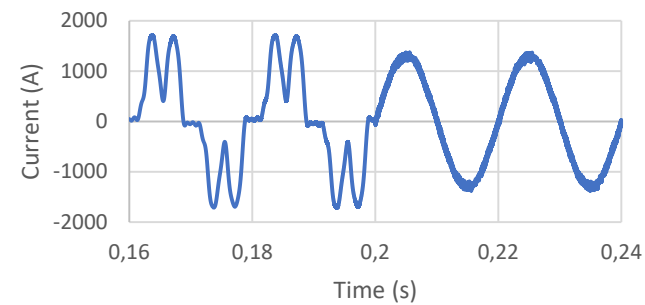

(a)

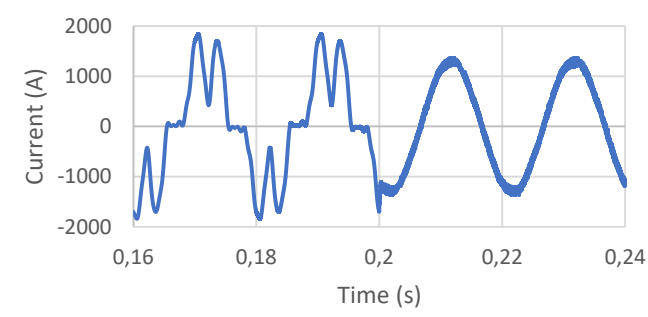

(b)

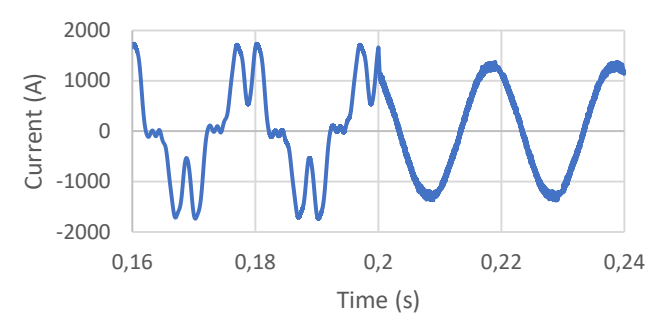

(c)

Fig. 10. Current waveforms of the combination of Chillers and HVAC loads, before and after the SAPF is turned-on, in instant $0.2 \mathrm{~s}$ : (a) L1 (b) L2 (c) L3.

Table 7. THD\%I and loads current values before and after filter's action.

\begin{tabular}{|l|c|c|c|c|}
\hline & \multicolumn{2}{|c|}{ Before Compensation } & \multicolumn{2}{c|}{ After Compensation } \\
\hline & THD\%I & Current Values (A) & THD\%I & Current Values (A) \\
\hline L1 & 46.89 & 1011 & 3.98 & 915 \\
\hline L2 & 45.06 & 1042 & 4.06 & 918 \\
\hline L3 & 44.68 & 1015 & 3.96 & 918 \\
\hline
\end{tabular}


Fig. 11shows the waveform of the reference currents produced by the control system and applied to the SAPF.

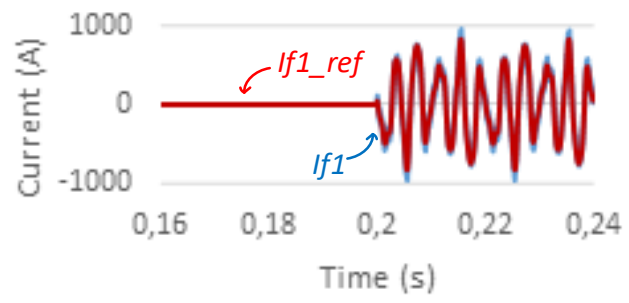

Fig. 11. Current waveform of the active power SAPF IfI and the reference generated by control system If1_ref, for the Chillers and HVAC system.

Fig. 12 shows the current produced by the SAPF in order to compensate the current of the loads. In this case the loads to compensate are the chiller and HVAC electrical switchboards.

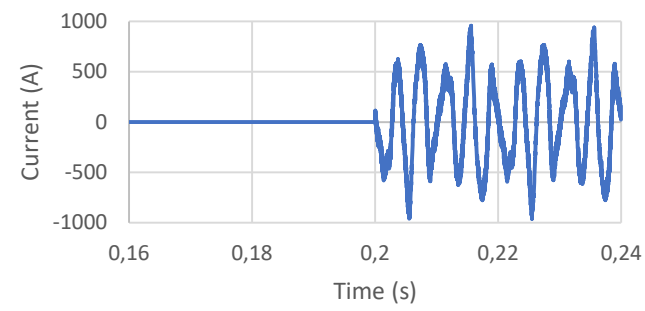

(a)

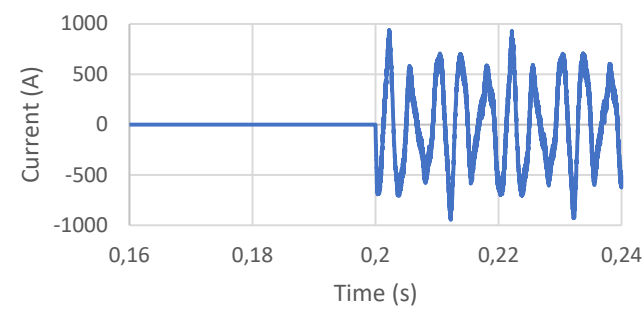

(b)

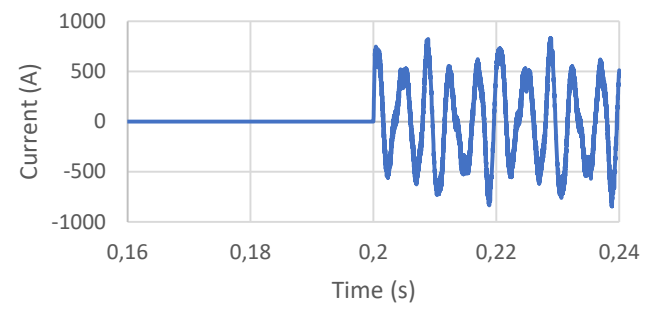

(c) 
Fig. 12. Current waveforms of the SAPF, before and after it starts its compensation: (a) L1 (b) L2 (c) L3.

It can be seen that the values of the currents produced by the SAPF are $437.1 \mathrm{~A}$ at L1, 431.3 A at L2 and 419 A at L3.

Fig. 13 shows the current values present in the neutral before and after the SAPF operation.

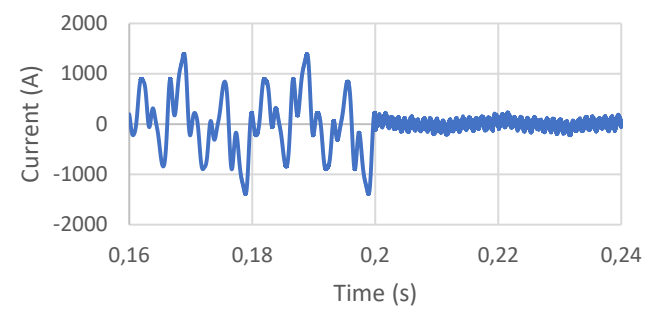

Fig. 13. Current waveform of neutral line, before and after the SAPF is turned-on in instant $0.2 \mathrm{~s}$.

It can be seen that before the SAPF operation the neutral current value is $642 \mathrm{~A}$, and that after the SAPF operation (instant $0.2 \mathrm{~s}$ ) the neutral current value is reduced to 65.7 A.

\section{$5.2 \quad$ Scenario 2}

In this second scenario, all the mentioned loads are connected to the system, but only the 10 electrical switchboards are being compensated. The results presented in Fig. 14 are the grid currents, when considering all the connected loads.

Fig. 14 shows the grid-side current values before and after the SAPF operation.

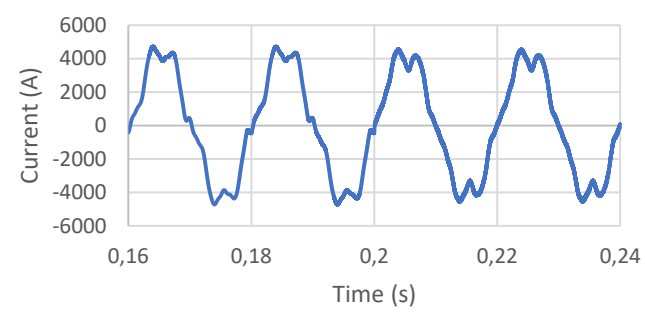

(a)

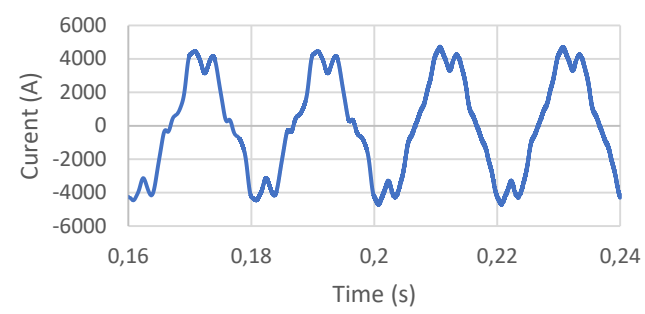


(b)

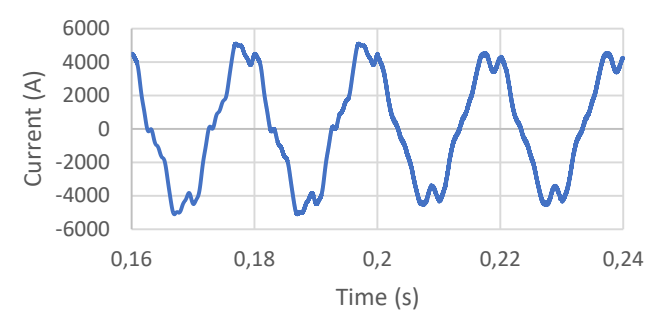

(c)

Fig. 14. Current waveform of the power grid, before and after the SAPF is turned-on in instant 0.2 s: (a) L1 (b) L2 (c) L3.

Before the SAPF operation, current values of $3168 \mathrm{~A}$ at L1, $2933 \mathrm{~A}$ at L2 and $3370 \mathrm{~A}$ at L3 are presented. Regarding THD\%I, values of $16.38 \%$ at L1, $20.59 \%$ at L2 and $16.70 \%$ at L3 are presented. At instant $0.2 \mathrm{~s}$ the SAPF is active and compensating. After this instant the values of current and THD\% I are reduced. It can be observed current values of $3041 \mathrm{~A}$ at L1, $3076 \mathrm{~A}$ at L2 and $3051 \mathrm{~A}$ at L3. Regarding THD\%I, values of $14.34 \%$ at L1, $14.14 \%$ at L3 and $13.82 \%$ at L3 are presented. Table 8 presents these results.

Table 8. THD\%I and grid current values before and after the filter's action.

\begin{tabular}{|l|c|c|c|c|}
\hline & \multicolumn{2}{|c|}{ Before Compensation } & \multicolumn{2}{c|}{ After Compensation } \\
\hline & THD\%I & Current Values (A) & THD\%I & Current Values (A) \\
\hline L1 & 16.38 & 3168 & 14.34 & 3041 \\
\hline L2 & 20.59 & 2933 & 14.14 & 3076 \\
\hline L3 & 16.70 & 3370 & 13.82 & 3051 \\
\hline
\end{tabular}

Fig. 15 illustrates the reference current generated by the control system in order to compensate the currents on the grid side.

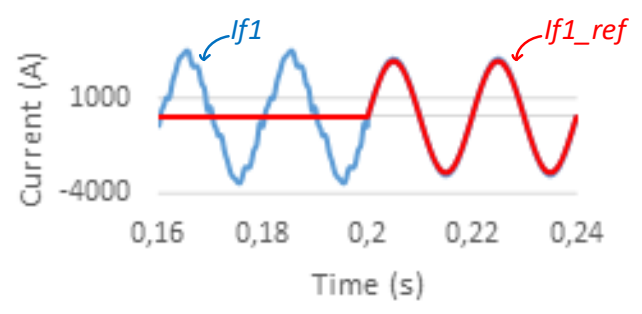

Fig. 15. Current waveform of the SAPF IfI and the reference generated by control system IfI_ref, for the electrical switchboard.

Fig. 16 presents the current values to be compensated by the SAPF (before $0.2 \mathrm{~s}$ ). In this case, this current refers to the electrical switchboards. 


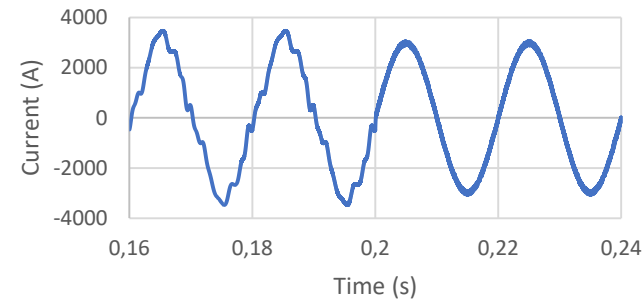

(a)

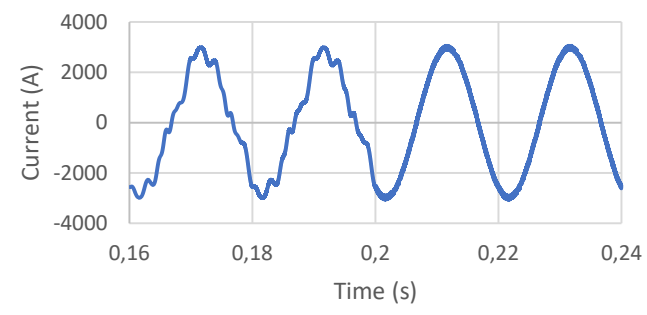

(b)

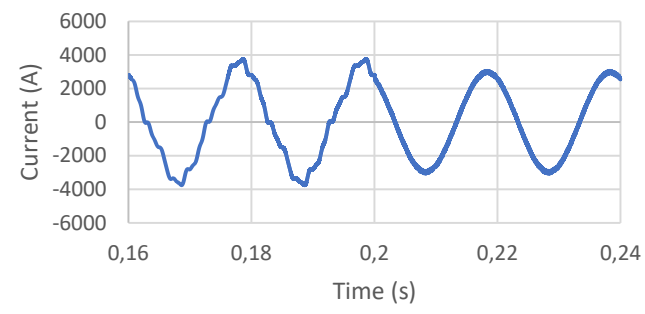

(c)

Fig. 16. Current waveforms of the electrical switchboards, before and after the SAPF is turned-on at instant $0.2 \mathrm{~s}$ : (a) L1 (b) L2 (c) L3.

Fig. 16 shows the currents before and after the operation of the SAPF. It can be seen that before the SAPF actuation, the current values are of $2225 \mathrm{~A}$ at L1, $1940 \mathrm{~A}$ at L2 and $2416 \mathrm{~A}$ at L3 are presented. Regarding THD\%I values of $11.09 \%$ at L1, $13.36 \%$ at L2 and $10.22 \%$ at L3 are presented. At instant $0.2 \mathrm{~s}$ the SAPF becomes active and begins to compensate. After this instant the values of current and THD\%I are reduced and current values of 2097 A at L1, 2097 A at L2 and 2097 A at L3 are observed. Regarding THD\%I, values of $1.70 \%$ at L1, $1.70 \%$ at L2 and $1.70 \%$ at L3 are presented. Table 9 presents these results.

Table 9. THD\%I and loads current values before and after the filter's action.

\begin{tabular}{|l|c|c|c|c|}
\hline & \multicolumn{2}{|c|}{ Before Compensation } & \multicolumn{2}{c|}{ After Compensation } \\
\hline & THD\%I & Current Values (A) & THD\%I & Current Values (A) \\
\hline L1 & 11.09 & 2225 & 1.70 & 2097 \\
\hline L2 & 13.36 & 1940 & 1.70 & 2097 \\
\hline
\end{tabular}


Fig. 17 shows the reference current calculated by the control system and which is applied to the SAPF.

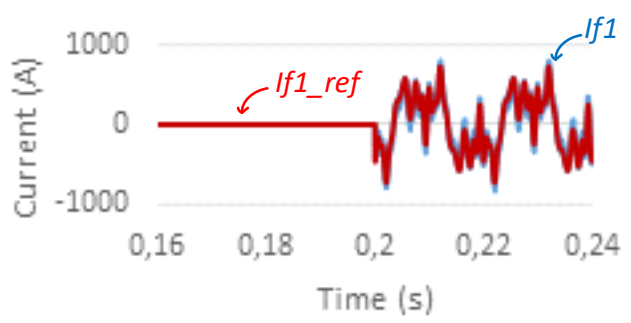

Fig. 17. Current waveform of the SAPF IfI and the reference generated by control system IfI_ref, for the electrical switchboards.

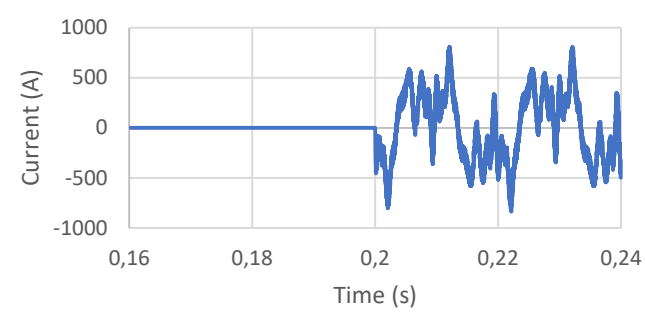

(a)

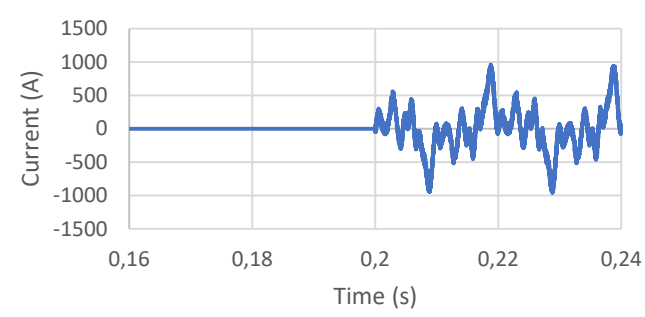

(b)

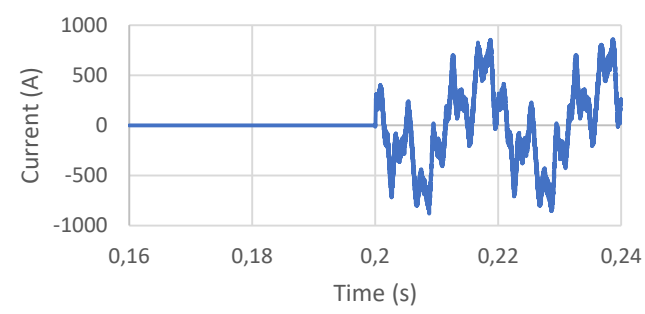

(c) 
Fig. 18. Current waveforms of the SAPF, before and after it starts its compensation: (a) L1 (b) L2 (c) L3.

Fig. 18 presents the SAPF current value which is of $346.7 \mathrm{~A}$ at L1, 337.8 A at L2 and 415.6 A at L3.

Fig. 19 shows the neutral current before and after the SAPF operation.

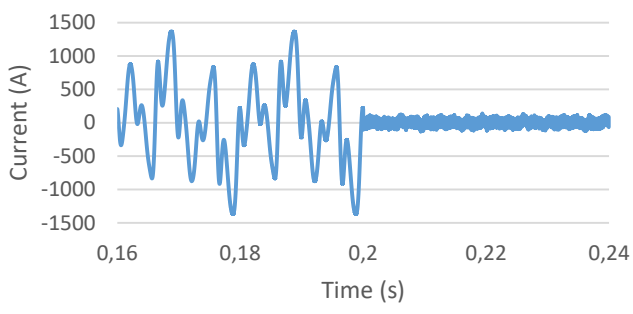

Fig. 19. Current waveform of neutral line, before and after the SAPF is turned-on in instant $0.2 \mathrm{~s}$.

It can be seen that before the SAPF actuation the current value is $640 \mathrm{~A}$ and that after the SAPF actuation, this current is reduced to $37.2 \mathrm{~A}$.

\section{Conclusions}

After analyzing the results obtained in simulation of the two different scenarios, it is possible to verify a reduction of THD\%I, a reduction of the current in the neutral, as well as a balance of currents among the three phases.

In the simulation presented in 5.1, there is a reduction of about $42 \%$ of THD\%I recorded after the operation of the SAPF, and a reduction of about $53.3 \%$ of the current in the neutral conductor.

Regarding the simulation presented in 5.2, there is a reduction of about $10 \%$ after the operation of the SAPF, and a reduction of about $94.2 \%$ of the current present in the neutral conductor.

It can also be seen that after the SAPF operation, the currents always present quite identical values throughout the three phases of the system, which translates into a balanced system. If two SAPF were applied, one for the production lines and another for the HVAC system, it is assumed that the reduction of THD\%I and neutral current would be even higher.

Thus, with the reduction of THD\%I and consequent reduction of the neutral current, problems associated with the malfunction of the machines in the factory will be avoided. Also, since there is less current circulating in the neutral conductor, it's overheating is avoid.

There will also be monetary savings associated with the cost of electricity. Even though the active power is maintained, the overall system's current is decreased. This results in fewer losses in the conductors and transformers. So, according to the results presented, the installation of the SAPF brings technical benefits to the electrical installation of the industrial complex. 
In summary, this article aims to present the benefits that a SAPF can bring to the plant installation, in order to prevent problems derived from harmonics and unbalances.

\section{Acknowledgment}

This work is supported by: European Structural and Investment Funds in the FEDER component, through the Operational Competitiveness and Internationalization Programme (COMPETE 2020) [Project n 39479; Funding Reference: POCI-01-0247FEDER-39479].

\section{References}

[1] H. Akagi, "New trends in active filters for improving power quality," Proc. IEEE Int. Conf. Power Electron. Drives Energy Syst. Ind. Growth, PEDES, vol. 1, pp. 417-425, 1996, doi: 10.1109/pedes.1996.539652.

[2] Z. Lin, G. Li, M. Zhou, and K. L. Lo, "Economic evaluation of real-time power quality cost," Proc. Univ. Power Eng. Conf., pp. 11-15, 2010.

[3] F. Shrouf, J. Ordieres, and G. Miragliotta, "Smart factories in Industry 4.0: A review of the concept and of energy management approached in production based on the Internet of Things paradigm," IEEE Int. Conf. Ind. Eng. Eng. Manag., vol. 2015-January, pp. 697-701, 2014, doi: 10.1109/IEEM.2014.7058728.

[4] N. Mohamed, J. Al-Jaroodi, and S. Lazarova-Molnar, "Industry 4.0: Opportunities for enhancing energy efficiency in smart factories," SysCon 2019 - 13th Аnnu. IEEE Int. Syst. Conf. Proc., 2019, doi: 10.1109/SYSCON.2019.8836751.

[5] K. Archana, M. S. Sumukha, and T. M. Mohammed, "Power Quality Improvement using Shunt Active Filter," Int. Conf. Curr. Trends Comput. Electr. Electron. Commun. CTCEEC 2017, no. 1, pp. 622-626, 2018, doi: 10.1109/CTCEEC.2017.8455197.

[6] W. Lu, C. Xu, and C. Li, "Selective compensation of power quality problems with a three-phase four-leg shunt active filter," Proc. World Congr. Intell. Control Autom., pp. 166-171, 2011, doi: 10.1109/WCICA.2011.5970721.

[7] J. Zhao, W. Dai, and K. Wang, "Shunt active power filter and its application," Int. Conf. Challenges Environ. Sci. Comput. Eng. CESCE 2010, vol. 2, pp. 373376, 2010, doi: 10.1109/CESCE.2010.208.

[8] R. Pregitzer, J. G. Pinto, M. João Sepúlveda, and J. L. Afonso, "Parallel association of shunt active power filters," IEEE Int. Symp. Ind. Electron., vol. 00, pp. 2493-2498, 2007, doi: 10.1109/ISIE.2007.4374999.

[9] J. G. Pinto, P. Neves, D. Gonçalves, and J. L. Afonso, "Field results on developed three-phase four-wire shunt active power filters," IECON Proc. (Industrial Electron. Conf., pp. 480-485, 2009, doi: 10.1109/IECON.2009.5414969.

[10] B. Singh, K. Al-haddad, S. Member, and A. Chandra, "Power Quality 
Improvement," October, vol. 46, no. 5, pp. 960-971, 1999.

[11] M. Popescu, A. Bitoleanu, V. Suru, and A. Patrascu, "High performance shunt active power filter," 2011 7th Int. Symp. Adv. Top. Electr. Eng. ATEE 2011, 2011.

[12] K. R. Chaudhari and T. A. Trivedi, "Analysis on control strategy of Shunt Active Power Filter for three-phase three-wire system," 2014 IEEE PES Transm. Distrib. Conf. Expo. PES T D-LA 2014 - Conf. Proc., vol. 2014October, pp. 0-5, 2014, doi: 10.1109/TDC-LA.2014.6955179.

[13] E. L. L. Fabricio, S. C. Silva, C. B. Jacobina, and M. B. D. R. Corrêa, "Analysis of Main Topologies of Shunt Active Power Filters Applied to Four-Wire Systems," IEEE Trans. Power Electron., vol. 33, no. 3, pp. 2100-2112, 2018, doi: 10.1109/TPEL.2017.2698439.

[14] M. Depenbrock, "The FBD-method, a generally applicable tool for analyzing power relations," ICHPS 1992 - Int. Conf. Harmon. Power Syst., pp. 135-141, 1992, doi: 10.1109/ICHPS.1992.559009.

[15] V. Staudt, "Fryze - Buchholz - Depenbrock : A time-domain power theory," Int. Sch. Nonsinusoidal Curr. Compens. 2008, pp. 1-12, 2008.

[16] M. Karimi-Ghartemani and M. R. Iravani, "A new phase-locked loop (PLL) system," in Proceedings of the 44th IEEE 2001 Midwest Symposium on Circuits and Systems. MWSCAS 2001 (Cat. No.01CH37257), 2001, vol. 1, pp. 421-424, doi: 10.1109/MWSCAS.2001.986202.

[17] A. Araujo, J. G. Pinto, B. Exposto, C. Couto, and J. L. Afonso, "Implementation and comparison of different switching techniques for shunt active power filters," IECON Proc. (Industrial Electron. Conf., pp. 1519-1525, 2014, doi: 10.1109/IECON.2014.7048703. 